\title{
A Case Report of Hepatopulmonary Syndrome
}

\author{
Liqiu Wu', Fan Su1, Muchao Huang2 \\ ${ }^{1}$ Department of Internal Medicine, The First Affiliated Hospital, Sun Yet-sen University, Guangzhou, China \\ ${ }^{2}$ Department of Internal Medicine, The Second Affiliated Hospital of Guangdong Pharmaceutical University, \\ Guangzhou, China \\ Email: laychard@163.com
}

Received 16 August 2015; accepted 12 September 2015; published 15 September 2015

Copyright (C) 2015 by authors and Scientific Research Publishing Inc.

This work is licensed under the Creative Commons Attribution International License (CC BY).

http://creativecommons.org/licenses/by/4.0/

(c) (7) Open Access

\begin{abstract}
Hepatopulmonary syndrome (HPS) is a severe complication of end-stage hepatic disease. However, the majority of HPS patients present with non-specific clinical manifestations and imaging features. They are constantly misdiagnosed as interstitial pneumonia, pulmonary infection or heart failure and appropriate treatment is thus delayed. In this report, clinical manifestations, diagnosis and treatment of one case of HPS were retrospectively analyzed and literature review was conducted. When the heapatic failure liver disease patients present with hypoxemia, pulmonary angiography, contrast echocardiography for right-sided heart (contrast enhanced echocardiogram) and lung perfusion scan (99mTc-MAA) should be done to exclude HPS. Orthotopic liver transplantation serves as the unique effective therapy of HPS.
\end{abstract}

\section{Keywords}

Hepatopulmonary Syndrome, Orthostatic Hypoxia, Intrapulmonary Vascular Dilatation, Orthotopic Liver Transplantation

\section{Introduction}

Hepatopulmonary syndrome (HPS) is a triad of advanced liver disease, intrapulmonary vasodilatation (IPVD), and arterial hypoxemia. The incidence of HPS in patients diagnosed with cirrhosis ranges from $10 \%$ to $30 \%$ [1], and HPS is occasionally noted in non-cirrhosis patients with portal hypertension. At present, there has been no consensus on diagnostic criteria. No effective therapy has been available. Consequently, HPS patients suffer from poor prognosis and high mortality rate. Early diagnosis and treatment contribute to improving clinical prognosis. The objectives of this article are to improve the early diagnosis of HPS and improve its prognosis by 
studying one case of HPS.

\section{Case Report}

A 35-year-old man, had lip and extremity cyanosis for 1 year and presented with shortness of breath and cough after physical activity for 6 months. He was diagnosed with hepatitis B with jaundice at the age of 19. Physical examination at age of 20 revealed leukopenia and thrombocytopenia, splenomegaly and was left untreated. During that period, he could still take intense sports activities. He had hemoptysis at age of 33 and was diagnosed with secondary hypersplenism, pulmonary capillarity angiorrhexis and hemorrhage, and chronic hepatitis B with cirrhosis. Then, he underwent splenectomy. Physical examination: body temperature $36.7^{\circ} \mathrm{C}$, respiration rate 29 breaths/minute, lip and extremity cyanosis, nevus araneus noted in the prothorax and hand back. The breath sound of bilateral lungs was coarse and slight moist rale was heard at the base of bilateral lungs. Liver function: AST 43 U/L, ALT 33 U/L, ALB 28 g/L and positive for hepatitis B surface antigen. Routine blood test: PT 25.8 s, INR 2.14 and APTT $48.0 \mathrm{~s}$. Blood gas analysis (without oxygen inhalation): when he was lay in a supine position, $\mathrm{pH}$ 7.48, $\mathrm{PaCO}_{2} 29 \mathrm{mmHg}, \mathrm{PaO}_{2} 44 \mathrm{mmHg}, \mathrm{P}_{\mathrm{A}-\mathrm{a}} \mathrm{O}_{2} 18 \mathrm{mmHg}, \mathrm{HCO}_{3}^{-} 21.6 \mathrm{mmol} / \mathrm{L}, \mathrm{BE}-0.8 \mathrm{mmol} / \mathrm{L}$ and $\mathrm{SaO}_{2} 83 \%$. When the patient was in an upright position, $\mathrm{pH} 7.48, \mathrm{PaCO}_{2} 26 \mathrm{mmHg}, \mathrm{PaO}_{2} 35 \mathrm{mmHg}, \mathrm{P}_{\mathrm{A}-\mathrm{a}} \mathrm{O}_{2}$ $25 \mathrm{mmHg}, \mathrm{HCO}_{3}^{-} 19.4 \mathrm{mmol} / \mathrm{L}, \mathrm{BE}-2.5 \mathrm{mmol} / \mathrm{L}$ and $\mathrm{SaO}_{2} 73 \%$ were obtained. Intraoperative selective bilateral pulmonary angiography found no direct large shunt between the pulmonary artery and vein. The venography was relatively rapid and diffuse small arteriovenous shunt was considered. No explicit pulmonary arteriovenous fistula was observed. Chest CT with intravenous contrast showed: increases in bilateral lung markings and lattice changes were noted at the periphery with blurry margins, especially apparent in the bilateral lung apex and subpleura area. Gastroscope: substantial quantity of tortuous and dilated vessels was noted in the esophageal lower segment and surrounding the stomach. The shadow of vascular dilation was observed. Contrast echocardiography for right-sided heart: ultrasound contrast agent (SonoVue) was injected via the left upper vein. The atrium dextrum was first visualized and then the right ventricle. The left atrium was immediately visualized after three cycles of heart heat and then the left ventricle. The diagnosis of pulmonary arteriovenous fistula was considered. Lung function: 1) Normal lung ventilation; 2) Sharp decline in lung diffusion and the DLCO accounted for $21 \%$ of the estimated value. The diagnosis of HPS was confirmed. The patient underwent orthotopic liver transplantation. Postoperatively, the symptoms of short breath and lip cyanosis were equally significantly alleviated. Reexamination of blood gas analysis: $\mathrm{pH}$ 7.40, $\mathrm{PaCO}_{2} 29 \mathrm{mmHg}, \mathrm{PaO}_{2} 81 \mathrm{mmHg}, \mathrm{P}_{\mathrm{A}-\mathrm{a}} \mathrm{O}_{2} 13 \mathrm{mmHg}$, $\mathrm{HCO}_{3}^{-} 19.4 \mathrm{mmol} / \mathrm{L}, \mathrm{BE}-2.5 \mathrm{mmol} / \mathrm{L}, \mathrm{SaO}_{2} 95 \%$ and $\mathrm{FiO}_{2} 21 \%$.

\section{Discussion}

\subsection{Diagnosis}

The reference diagnostic criteria of HPS: 1) Chronic liver disease, persistent hepatic injury, especially portal hypertension, nevus araneus, liver palm or drumstick finger (toe). 2) Hypoxemia and orthostatic hypoxia unrelated to heart and lung diseases are pivotal characteristics of HPS. 3) Gas exchange abnormalities: $\mathrm{P}_{\mathrm{A}-\mathrm{a}} \mathrm{O}_{2}>15$ $\mathrm{mmHg}$ or $\mathrm{PaO}_{2}<80 \mathrm{mmHg}$ [2].

The severity of HPS hypoxemia is not significantly correlated with liver function test [3]. Orthostatic hypoxia is the unique manifestation of HPS. The level of $\mathrm{PaO}_{2}$ decreased by $5 \%$ or by over $4 \mathrm{mmHg}$ in an upright position. The changes in the $\mathrm{P}_{\mathrm{A}-\mathrm{a}} \mathrm{O}_{2}$ level are more sensitive compared with those of $\mathrm{PaO}_{2} \cdot \mathrm{P}_{\mathrm{A}-\mathrm{a}} \mathrm{O}_{2}$ level has become a major factor for HPS diagnosis. If the patients with liver diseases had $\mathrm{P}_{\mathrm{A}-\mathrm{a}} \mathrm{O}_{2}>15 \mathrm{mmHg}$, then the diagnosis of IPVD and HPS can be confirmed. $\mathrm{PaO}_{2}$ serves as a classification index for the severity of HPS: $\mathrm{PaO}_{2}>80$ mmHg for mild HPS, $60 \mathrm{mmHg}<\mathrm{PaO}_{2}<80 \mathrm{mmHg}$ for moderate $\mathrm{PaO}_{2}, \mathrm{PaO}_{2}<60 \mathrm{mmHg}$ or $>50 \mathrm{mmHg}$ for severe $\mathrm{PaO}_{2}$ and $\mathrm{PaO}_{2}<50 \mathrm{mmHg}$ for extremely severe HPS [2].

Digital subtraction angiography of the lung is regarded as an approach for confirming diagnosis of lung vascular abnormalities and provides imaging basis for the classification of HPS. Typical manifestations of HPS angiography are divided into two types [4]: for type I (84\%), no abnormality or diffuse lung telangiectasis was noted, manifested as lung spider- or sponginess-shaped shadow, suitable for liver transplantation; for type II patients, interrupted arteriovenous communicating branch was seen as solitary earthworm- or slump-shaped shadow. Pulmonary embolism surgery is considered for type II patients. Digital subtraction angiography of the lung confirmed that the specificity of lung vasodilatation is high. However, HPS dilation mainly involves with capillary 
vessels and adjacent mild arteriovenous malformation. Several HPS patients are merely manifested as capillary vessel dilation under microscope. Consequently, pulmonary angiography has a low sensitivity for the diagnosis of HPS and tends to yield false negative outcomes. At present, pulmonary angiography is mainly applied to select the treatment plans for HPS patients who are scheduled for surgery.

Currently, two approaches are commonly employed to confirm the diagnosis of IPVD: 1) Contrast enhanced echocardiogram (CEE) is a sensitive, qualitative non-traumatic examination tool of intrapulmonary shunt. It is considered as the most reliable approach for the diagnosis of HPS and negative outcomes can exclude the possibility of HPS. It has been reported that the positive rate of CEE is $11 \%$ to $47 \%$ in patients diagnosed with cirrhosis. A large proportion of them have normal blood oxygen. 2) Lung perfusion scan: systemic scan was performed after intravenous bolus injection of macro-aggregated albumin labeled with technetium $99 \mathrm{~m}$ (99mTcMAA). The advantage of lung perfusion scan is quantitative analysis of intrapulmonary shunt volume. It has been widely recognized that intrapulmonary arteriovenous shunt occurs when the radioactive intake of brain tissue and liver $\geq 6 \%$ [4]. The complication of basic lung diseases also prompts the percentage of oxygenation disorders induced by intrapulmonary shunt. This examination also contributes to evaluate the prognosis of HPS patients. One prospective study demonstrated that extrapulmonary intake of MAA $\geq 20 \%$ can enhance the mortality of liver transplantation. However, it fails to distinguish intracardiac from intrapulmonary shunt and the sensitivity is lower compared with that of CEE. Negative outcomes can not fully exclude the possibility of HPS.

In this case, the diagnosis of HPS was fully validated by history of chronic liver disease, orthostatic hypoxia and positive results of contrast enhanced echocardiogram. Selective digital subtraction angiography of pulmonary artery hinted the existence of diffuse small arteriovenous shunt.

\subsection{Treatment}

Besides symptomatic supportive therapies including treatment of primary disease and oxygen supplementation, lung angiotonics and NO inhibitor are mainly used in clinical practice. However, the clinical efficacy of medical therapy is not satisfactory. Transjugular intrahepatic portosystemic shunt (TIPS) yields insignificant efficacy in treating HPS. Application of potential arteriovenous shunt serves as a successful treatment of embolization [6]. Orthotopic liver transplantation is regarded as the unique effective treatment for HPS. In this case, the symptom of hypoxemia was completely alleviated after orthotopic liver transplantation. The long-term mortality of HPS patients is significantly higher compared with that of non-HPS counterparts [5] [6].

A case-control clinical study [6] analyzed the effect of liver transplantation upon the prognosis of HPS patients and demonstrated that the mortality of HPS patients undergoing liver transplantation was $21 \%$, significantly lower than $78 \%$ of those not receiving liver transplantation. The median survival of HPS patients was 24 month, significantly shorter than 87 months of non-HPS patients with chronic liver disease. The 5-year survival of HPS patients was $23 \%$, considerably lower compared with $63 \%$ of non-HPS counterparts $(P=0.0003)$. Following orthotopic liver transplantation, the saturation oxygen of HPS patients was significantly improved. The reliance on oxygen was completely corrected. Meantime, HPS and non-HPS patients shared similar long-term survival rates.

\section{Conclusion}

HPS is commonly misdiagnosed, mainly due to insidious onset, non-specific clinical manifestations and nonspecific imaging characteristics. Contrast echocardiography for right-sided heart and lung perfusion scan through 99mTc-MAA are difficult to be widely applied in primary care settings. Consequently, HPS should be highly suspected at the presence of hypoxemia in patients with hepatic diseases. The performance of pulmonary angiography, contrast echocardiography for right-sided heart (contrast enhanced echocardiogram) and lung perfusion scan (99mTc-MAA) should be further enhanced. At present, orthotopic liver transplantation serves as the unique effective therapy of HPS. But the mortality of HPS patients after liver transplantation is still as high as $33 \%$, future studies are warranted to develop definitive effective therapies.

\section{References}

[1] Grace, J.A. and Angus, P.W. (2013) Hepatopulmonary Syndrome: Update on Recent Advances in Pathophysiology, Investigation and Treatment. Journal of Gastroenterology and Hepatology, 28, 213-219. 
http://dx.doi.org/10.1111/jgh.12061

[2] Rodríguez-Roisin, R., Krowka, M.J., Hervé, P. and Fallon, M.B., on behalf of the ERS Task Force Pulmonary-Hepatic Vascular Disorders (PHD) Scientific Committee ERS Task Force PHD Scientific Committee (2004) Task Force Pulmonary-Hepatic Vascular Disorders (PHD) Scientific Committee. Pulmonary-Hepatic vascular Disorders (PHD). European Respiratory Journal, 24, 861-880. http://dx.doi.org/10.1183/09031936.04.00010904

[3] Sztrymf, B., Rabiller, A., Nunes, H., et al. (2004) Prevention of Hepatopulmonary Syndrome and Hyperdynamic State by Pentoxifylline in Cirrhotic Rats. European Respiratory Journal, 23, 752-758. http://dx.doi.org/10.1183/09031936.04.00080404

[4] Li, P., Pu, J., et al. (2014) Hepatopulmonary Syndrome: Recent Advances in Pathogenesisi, Diagnosis and Treatment. Chinese Journal of Digestion and Medical Imageology (Electronic Edition), 4, 33-37.

[5] Swanson, K.L., Wiesner, R.H. and Krowka, M.J. (2005) Natural History of Hepatopulmonary Syndrome: Impact of Liver Transplantation. Hepatology, 41, 1122-1129. http://dx.doi.org/10.1002/hep.20658

[6] Schenk, P., Schöniger-Hekele, M., Fuhrmann, V., Madl, C., Silberhumer, G. and Müller, C. (2003) Prognostic Significance of the Hepatopulmonary Syndrome in Patients with Cirrhosis. Gastroenterology, 125, 1042-1052. http://dx.doi.org/10.1016/S0016-5085(03)01207-1 